\title{
The Normal Epithelium of Crypts Accruing Below Nonpolypoid Adenomas Thrives With Relocated Proliferating Cell-domains and p53-Up-regulated Cells
}

\author{
CARLOS A. RUBIO ${ }^{1}$ and PETER T. SCHMIDT ${ }^{2}$ \\ ${ }^{1}$ Department of Pathology, Karolinska Institute and University Hospital, Stockholm, Sweden; \\ ${ }^{2}$ Department of Medicine, Center for Digestive Diseases, Solna, \\ Karolinska Institute and University Hospital, Stockholm, Sweden
}

\begin{abstract}
Background/Aim: Colonic crypts with normal epithelium albeit with corrupted shapes (CCS) were previously found beneath nonpolypoid adenomas (NPA). This study aimed to analyze the distribution of proliferating cells (PC) and p53-up-regulated cells in CCS. Materials and Methods: Sections from 48 NPA were immunostained with the proliferating-marker Ki67 and against the tumor-suppressor protein p53. Results: Asymmetric-haphazardly distributed PC were found in $87.5 \%$ of the NPA, continuous PC-domains in $8.3 \%$, asymmetric-haphazardly distributed single PC in $4.2 \%$ and p53-up-regulated cells in 29.2\%. In 12 controls, the normal-shaped crypts revealed symmetrically-distributed PCdomains in their lower thirds, and no p53-up-regulated cells. Conclusion: The normal epithelium that lines the CCS below NPA, thrives with relocated PC-domains, and with occasional p53-up-regulated cells. These findings strongly suggest that the normal epithelium of CCS beneath NPA might harbor somatic mutations. The accretion of putative mutated CCS might play an important role in the evolution of nonpolypoid adenomas in the human colon.
\end{abstract}

In 1985 Muto et al., detected at colonoscopy, small nonpolypoid mucosal lesions measuring up to one $\mathrm{cm}$ in diameter (1). At histologic examination, those lesions were found to be adenomas. Flat adenomas (FA), as they were called, were subsequently found associated with a more aggressive clinical behavior than their polypoid counterpart (2).

Correspondence to: Carlos A. Rubio, MD, Ph.D., Gastrointestinal and Liver Pathology Research Laboratory, Department of Pathology, Karolinska Institute and University Hospital, 17176, Stockholm, Sweden. Tel: +46 851774527, Fax: +46 851774524, e-mail: Carlos.Rubio@ki.se

Key Words: Nonpolypoid adenomas, colon crypts, corrupted shapes, cell proliferation, p53-up-regulation.
The further improvement of optical devices together with the use of mucosal dyes, permitted endoscopists to more easily visualize previously undetected FA. In 1994, Jaramillo et al. (3) identified by the aid of high-resolution video colonoscopy and chromoscopy, a colon carcinoma arising in a FA. In 1995, the same group reported a collection of 109 flat neoplastic lesions: 97\% were FA and the remaining 3\%, FA with submucosal invasion (4). In 1999, one of us (CAR), trained in Western and Japanese pathology (5), reviewed 781 FA collected at the four main Hospitals in Tokyo, Japan and at the Karolinska Hospital, Stockholm, Sweden (6). The results showed that high-grade dysplasia was present in $42 \%$ out of 420 FA in Japanese patients, but only in $14 \%$ of the 361 FA in Swedish patients. Intramucosal or submucosal carcinomas were found in $15 \%$ of the FA in Japan, but only in $3 \%$ of the FA excised in Sweden (6). Thus, Japanese patients had more advanced FA (in terms of high-grade dysplasia) and more aggressive FA (in terms of intramucosal and submucosal invasion) than Swedish patients $(6,7)$. Those findings confirmed the claims of histological differences between flat colonic neoplasias in Japan and in Western countries $(8,9)$. According to Gotoda, the differences in the histological classification of gastrointestinal epithelial neoplasias between Western and Japanese pathologists, have been largely resolved by adopting the Vienna classification $(10,11)$.

In 1997, Kudo et al. reported non-polypoid (flat) colon neoplasms with a lateral diameter greater than $10 \mathrm{~mm}$; they were called laterally-spreading tumors (LST) (12). In subsequent surveys, Kim et al. (13) found that $85 \%$ of the 497 LSTs were nonpolypoid adenomas, Zhao et al. (14) that $88 \%$ of the 239 LST were nonpolypoid adenomas and Tang et al. (15) that all $33(100 \%)$ LST investigated were nonpolypoid adenomas. From the above, it is evident that nonpolypoid adenomas account for the majority of the FA and LST lesions in the human colon. Of note, Sato et al. (16) followed-up 14 patients with flat colonic tumors with colonoscopic examinations for 19 months (range=11-26 months). During that 
time interval, none of the flat tumors measuring approximately $5 \mathrm{~mm}$ in diameter progressed to LST. Notwithstanding, it remained unclear as to whether LST evolved in situ as fully developed neoplastic lesions from the start, or progress through the lateral extension of pre-existing FA.

In previous studies, we found beneath the adenomatous tissue of polypoid conventional adenomas (CoA), both in rats (17) and in humans (18), accruing colonic crypts lined with normal epithelium albeit with corrupted shapes (CCS). More recently, we found abnormally distributed proliferating cells (PC) and p53-up-regulated cells in CCS beneath the neoplastic canopy of polypoid CoA (19).

The crucial question was: Could the CCS found beneath the neoplastic tissue of nonpolypoid adenomas (20) also exhibit a disparate distribution of PC and reveal p53 upregulated cells? In attempts to answer these questions, we explored the distribution of proliferating cells and the possible occurrence of p53 immuno-reactive cells in CCS found in a cohort of nonpolypoid adenomas.

\section{Patients and Methods}

The material consists of sections from 48 endoscopically-removed nonpolypoid colon adenomas (NPA), without submucosal invasion. Histological sections ( $4 \mu \mathrm{m}$-thick) were retrieved from the files of the Gastrointestinal Research Laboratory of this Department, stained with hematoxylin and eosin (H\&E), and immuno-stained with the proliferation marker Ki67 (batch MIB1, DAKO Automation, 2600 Glostrup, Denmark), and the primary mouse monoclonal antibody (IgG1, kappa) directed against human tumor suppressor p53 protein (antip53, DO-7; Ventana Medical System, Inc, Roche, Basel, Switzerland).

PC and p53 up-regulated cells in CCS. Using 10x oculars and a $4 \mathrm{x}$ Apo objective (aperture number 0.20), the Field of Vision (FOV) was $5 \mathrm{~mm}$ in diameter. At this magnification, all Ki67 labelled and p53 up-regulated cells in CCS could easily be identified. p53 upregulated cells were regarded only those having the same intense immunoreactivity for the $\mathrm{p} 53$ tumor-suppressor protein as those in the neoplastic tissue on top.

$P C$ in normal colon crypts from historical controls. Sections from 12 grossly normal colonic segments proximal or distal to the surgically removed colonic adenocarcinoma were immunostained with Ki67 (batch MIB1). The PC distribution in the crypts were assessed using a $5 \mathrm{~mm}$ FOV20.

Statistical analysis. The non-parametric Kruskal-Wallis test was applied, to compare difference between groups. Statistical significance was defined as $p<0.05$.

This study was approved by The Regional Ethical Review Board in Stockholm (No. 2018/113-32 and 2018/688-32).

\section{Results}

PC phenotypes in CCS. When the Ki67 antibody reacts with its cognate antigen, all transit amplifying daughter cells
Table I. The frequency of predominant proliferating cells $(P C)$ phenotypes in crypts with normal epithelial lining but with corrupted shapes (CCS) found underneath the neoplastic canopy in 48 nonpolypoid adenomas of the colon.

\begin{tabular}{lc}
\hline Predominant PC phenotype & No. cases $(\%)$ \\
\hline Haphazardly distributed PC clusters* & $42(87.5 \%)$ \\
Continuous PC-domain & $4(8.3 \%)$ \\
Haphazardly-distributed Single PC & $2(4.2 \%)$ \\
\hline Total & $48(100 \%)$ \\
\hline
\end{tabular}

$* \geq$ two consecutive PC.

(TADs) become labelled. The following PC-phenotypes were detected in the 48 NPA: i) haphazardly distributed PC clusters ( $\geq$ two consecutive PC), ii) continuous PC-domain in one or in both sides of entire crypts, and iii) haphazardlydistributed single PC. Since the PC-distribution in CCS could vary in individual NPA, the predominant PCphenotype in CCS was selected. The intense PC found in the adenomatous tissue above CCS officiated as internal controls.

The distribution of PC in normal epithelium of CCS below the neoplastic tissue of nonpolypoid adenomas. The frequency of predominant PC-phenotypes in the CCS from the $48 \mathrm{NPA}$ is condensed in Table I; examples of PCphenotypes are illustrated in Figure 1 (upper panel). The Table shows that CCS with asymmetric, haphazardly distributed PC-clusters were recorded in $87.5 \%(42 / 48)$ of the NPA, with continuous PC in one or both slopes of the crypts, in $8.3 \%$ (4/48), and with haphazardly distributed single PC in the remaining $4.2 \%(2 / 48)$. The difference between NPA with CCS exhibiting haphazardly distributed PC-clusters and the other two groups in Table I, was significant $(p<0.05)$.

p53 up-regulated cells in the neoplastic tissue of nonpolypoid adenomas. The tumor-suppressor protein p53 was overexpressed in the adenomatous tissue in $39.6 \%$ (19/48) of the NPA. This percentage was somewhat higher than that found in a previous survey at this department, where $25 \%$ out of the 433 polypoid conventional adenomas showed p53overexpression in the neoplastic tissue (21).

p53 up-regulated cells in CCS below the neoplastic tissue of nonpolypoid adenomas. In 29.2\% (14/48), the CCS beneath NPA showed p53-up-regulated cells; examples are illustrated in Figure 1 (lower panel). No p53-up-regulated cells could be demonstrated in the CCS in the remaining $70.8 \%(34 / 48)$. 


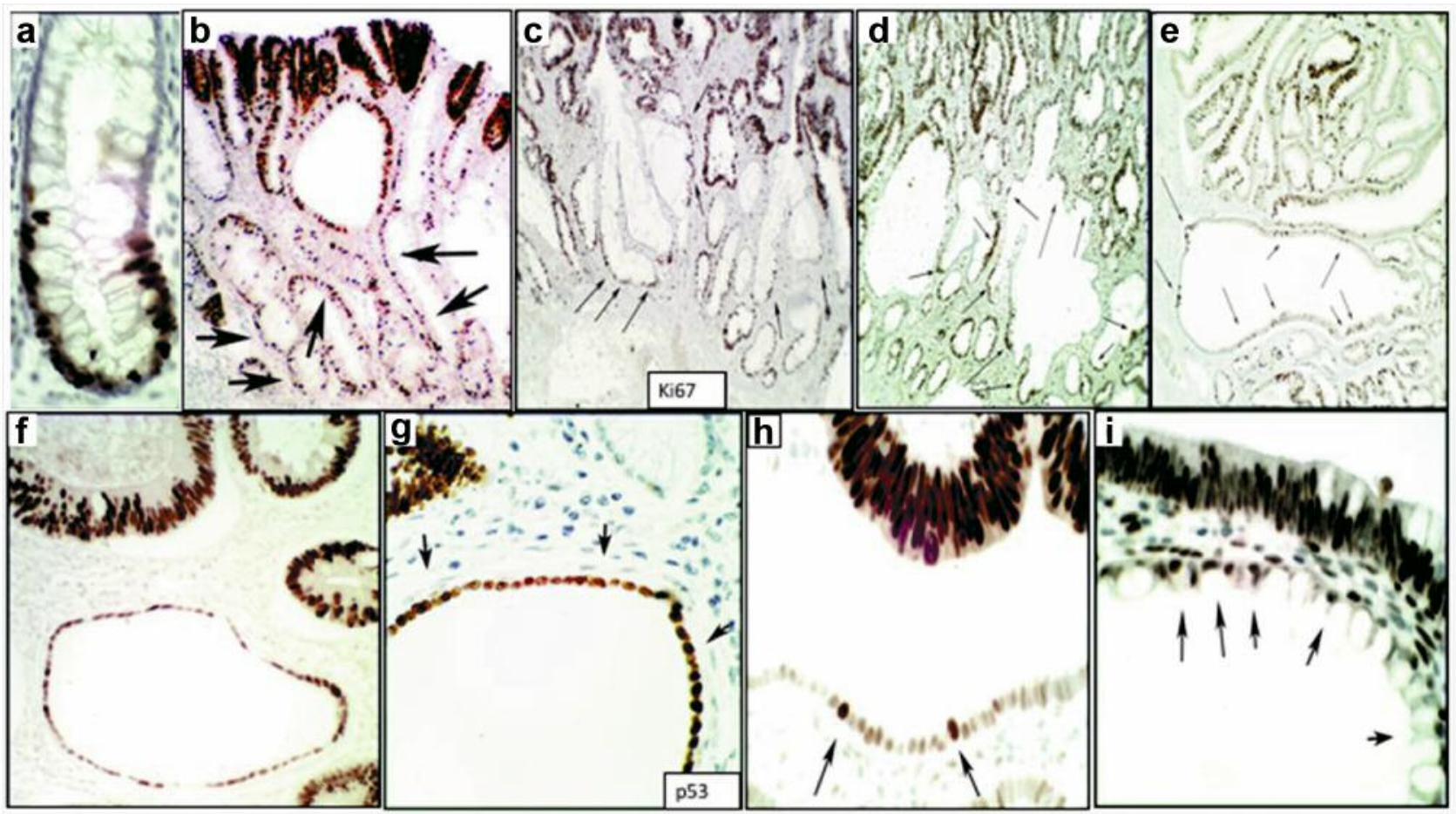

Figure 1. Cell proliferation and p53-up-regulated cells in the normal epithelium of crypts with disparate shapes found beneath nonpolypoid colon adenomas. Upper panel; a: Proliferating cells $(P C)$ in a control crypt (normal colon). Note symmetrically-aligned PC, in both slopes of the lower third of the crypt (control, Ki67, batch MIB1, original x40), b to e: Cell proliferation in crypts lined with normal epithelium although with corrupted shapes (CCS) found below the neoplastic tissue of nonpolypoid adenomas (NPA), b: Crypts lined with normal epithelium but with CCS found below the neoplastic tissue of a NPA (on top). Note asymmetric-haphazardly distributed PC-domains (Ki67, batch MIB, original $\times 20)$, c, d, e: Dilated CCS displaying disparate distributions of PC (Ki67, batch MIB, $\times 10)$. Lower panel; $f$ - $i$ : p53-upregulated cells (arrows) in crypts lined with normal epithelium although with CCS found below the neoplastic tissue of NPA. Note the neoplastic tissue of nonpolypoid adenomas on top (p53 immunostaining, $f$ : original $\times 20$, g: original $\times 40$, h and $f$ : original $\times 40)$.

\section{Discussion}

This study showed that the normal epithelium of CCS -an integral component of colonic NPA- harbors disparate, haphazardly distributed PC, often in asymmetric PC-clusters or as single PC and unexpectedly, haphazardly distributed p53 up-regulated cells. It became apparent that the CCS underneath NPA thrive with an anomalous operational makeup. In contrast, the normal crypts from control cases displayed symmetrically aligned PC lengthwise their lower thirds, and showed no p53-up-regulated cells.

In the normal colon, the stem cells are located at the base of crypts; stem cells synchronize the repopulation of the crypts by generating progenitor cells called transient amplifying daughter (TAD) cells (22-24). Progenitor cells [120 to $150 \mathrm{TAD}$ cells/crypt according to Testa et al. (25)] account for the bulk of the PC in the crypts. Since in normal crypts the PC are generated by stem cells (22-24), the occurrence of multiple PC-domains in the TADs of CCS, rationally implies that several stem cells exist in these crypts. This deduction is in concert with studies in humans by Baker et al. (22), showing that 5 to 6 stem cells are to be found in each normal colon crypt. Thus, at variance with the natural position of stem cells at the base of normal crypts (26-28), the stem cells in CCS seem to have been relocated (rearranged?). The relocation of the normal position of PC in CCS and the presence of up-regulated p53-domains in the normal epithelium of CCS in $29 \%$ of the NPA, support the notion that their normal-looking epithelium might had been subjected to somatic mutations.

The crucial question is why some adenomas are nonpolypoid while others are polypoid? In this regard, Voorham et al. (29) found that the patterns of DNA copy number changes differed between the two phenotypes. Whereas loss of 5q14.3 and 5q15-q3 were significantly more frequent in flat adenomas, losses of 1p36.32-p35.3, 10q25.3, $17 \mathrm{p} 12$, and chromosome 18 were more frequent in polypoid adenomas (29). In addition, APC mutations were more 
frequent in polypoid adenomas compared to flat adenomas, suggesting that the disruption of the Wnt-pathway may occur via different mechanisms in these two phenotypes (30). Takahashi et al. (31) also found genetic alterations that might play an important role in the development of flat-type advanced adenomas, especially in the distal colon. Epigenetic alterations occurred infrequently in flat-type advanced adenomas, suggesting that they have different genetic and epigenetic alterations than those in protrudedtype advanced adenomas (31). From the above it is evident that the molecular make-up in NPA is different to that in polypoid adenomas. Voorham et al. (29) found no significant association between the different morphological phenotypes and mutations in key genes of the RAS-RAF-MAPK.

Another pertinent question is: Which are the morphogenetic mechanisms that induce colonic crypts, lined with normal epithelium, to assume corrupted shapes beneath NPA? Morphogenesis stands for the ability of a system to change its form. Jagan et al. (32) demonstrated that the formation of colorectal crypts is regulated by phosphatase and tensin homologue deleted on chromosome 10 (PTEN), a protein encoded by the PTEN gene (32). In addition, Georgescu et al. (33) in three-dimensional studies of human colon glands, found that NHERF1 protein, a $\mathrm{Na}^{+} / \mathrm{H}^{+}$ exchanger regulatory factor, controls gland morphogenesis. Thus, the CCS-phenotype in NPA might have been generated by alterations in morphogenesis-signals such as NHERF1 and PTEN.

Goodblad et al. (34) showed that there are up to 15 times more mitotic figures in a whole colonic crypt than in the $4 \mu \mathrm{m}$-thick histological sections that were used in their studies. Since the number of proliferating cells/crypt is much higher than the number of mitotic cells/crypt (34), it is not inconceivable that CCS showing an aberrant PC pattern could contain a higher number of DNA-synthetizing cells or clusters elsewhere, in other areas from the same crypt. It should be stressed that to assess PC in NPA, we also used 4 $\mu$ m-thick sections.

Boman and Fields (24), stated that normal crypts began to show abnormalities in histology only when they became dysplastic. In contrast, we found that the normal epithelium of CCS in NPA (35-37) had already experienced profound biomolecular alterations.

In sum, the normal epithelium in CCS accruing beneath NPA in the colon disclosed an unprecedented relocation (reorganization?) of PC-domains. Rationally, the relocation of PC might had been preceded by the relocation of the cells that fuel PC, namely the stem cells (22-24). In addition, the CCS of a fraction of NPA disclosed p53-up-regulated cells, strongly suggesting that the normal epithelium in those crypts might harbor somatic mutations. Considering that human colonic crypts typically divide at most once or twice during a lifetime, with an average crypt cycle length of 36 years (22), the accretion of putative mutated CCS emerges as a major event that might play an important role in the evolution of NPA in the human colon.

\section{Conflicts of Interest}

The Authors declare no competing interests regarding this study.

\section{Authors' Contributions}

CAR: Designed the experiment, performed procedures, data analysis and wrote the manuscript; PTS harvested endoscopically nonpolypoid adenomas, introduced suggestions and approved the final manuscript.

\section{References}

1 Muto T, Kamiya J, Sawada T, Konishi F, Sugihara K, Kubota Y, Adachi M, Agawa S, Saito Y and Morioka Y: Small "flat adenoma" of the large bowel with special reference to its clinicopathologic features. Dis Colon Rectum 28: 847-851, 1985. PMID: 4053897. DOI: 10.1007/bf02555490

2 Kudo Se, Lambert R, Allen JI, Fujii H, Fujii T, Kashida H, Matsuda T, Mori M, Saito H, Shimoda T, Tanaka S, Watanabe H, Sung JJ, Feld AD, Inadomi JM, O'Brien MJ, Lieberman DA, Ransohoff DF, Soetikno RM, Triadafilopoulos G, Zauber A, Teixeira CR, Rey JF, Jaramillo E, Rubio CA, Van Gossum A, Jung M, Vieth M, Jass JR and Hurlstone PD: Nonpolypoid neoplastic lesions of the colorectal mucosa. Gastrointest Endosc 68(4 Suppl): S3-47, 2008. PMID: 18805238. DOI: 10.1016/ j.gie.2008.07.052

3 Jaramillo E, Slezak P, Watanabe M and Rubio CA: Endoscopic detection and complete removal of a micro-invasive carcinoma present in a flat colonic adenoma. Gastrointest Endosc 40: 369371, 1994. PMID: 8056247. DOI: 10.1016/s0016-5107(94) 70077-x

4 Jaramillo E, Watanabe M, Slezak P and Rubio CA: Flat neoplastic lesions of the colon and rectum detected by high resolution video endoscopy and chromoscopy. Gastrointest Endosc 42: 114-122, 1995. PMID: 7590045. DOI: 10.1016/ s0016-5107(95)70066-8

5 Rubio CA, Kato Y, Hirota and Muto T: Histologic classification of endoscopically removed flat colorectal polyps: a multicentric study. Jpn J Cancer Res 87: 849-855, 1996. PMID: 8797892. DOI: $10.1111 / j .1349-7006.1996 . t b 02110 . x$

6 Rubio CA, Saito Y, Watanabe M, Koizumi K, Takahama KK, Hirata I, Nakano H, Jaramillo E, Slezak P, Kumagai J, Nakamura $\mathrm{K}$, Yanagisawa A, Kato Y, Kawaguchi M, Miyaoka M, Horimukai H, Taguchi Y, Katayama A, Hirota T, Watanabe, Masaki T and Muto T: Non-polypoid colorectal neoplasias: A multicentric study. Anticancer Res 19: 2361-2364, 1999. PMID: 10472356.

7 Rubio CA: Nonprotruding colorectal neoplasms: epidemiologic viewpoint. World J Surg 24: 1098-1103, 2000. PMID: 11036288.

8 Church JM, Muto T and Appau K: Flat lesions of the colorectal mucosa: differences in recognition between Japanese and American endoscopists. Dis Colon Rectum 47: 1462-1466, 2004. PMID: 15486742. DOI: 10.1007/s10350-004-0608-x 
9 Kudo S: Flat and depressed types of early colorectal cancers: From East to West. Gastrointest Endoscopy Clin N Am 18: 581-593, 2008. PMID: 18674705. DOI: 10.1016/j.giec. 2008.05 .013

10 Schlemper RJ, Riddell RH, Kato Y, Borchard F, Cooper HS, Dawsey SM, Dixon MF, Fenoglio-Preiser CM, Fléjou JF, Geboes K, Hattori T, Hirota T, Itabashi M, Iwafuchi M, Iwashita A, Kim YI, Kirchner T, Klimpfinger M, Koike M, Lauwers GY, Lewin KJ, Oberhuber G, Offner F, Price AB, Rubio CA, Shimizu M, Shimoda T, Sipponen P, Solcia E, Stolte M, Watanabe $\mathrm{H}$ and Yamabe $\mathrm{H}$ : The Vienna classification of gastrointestinal epithelial neoplasia. Gut 47: 251-255, 2000. PMID: 10896917. DOI: 10.1136/gut.47.2.251

11 Gotoda T: Endoscopic resection for premalignant and malignant lesions of the gastrointestinal tract from the esophagus to the colon. Gastrointest Endoscopy Clin N Am 18: 435-450, 2008. PMID: 30842959. DOI: 10.12998/wjcc.v7.i4.482

12 Kudo S, Kashida H, Nakajima T, Tamura $\mathrm{S}$ and Nakajo K: Endoscopic diagnosis and treatment of early colorectal cancer. World J Surg 21: 694-701, 1997. PMID: 9276699.

13 Kim HH, Kim JH, Park SJ, Park MI and Moon W: Risk factors for incomplete resection and complications in endoscopic mucosal resection for lateral spreading tumors. Dig Endosc 24: 259-266, 2012. PMID: 22725112. DOI: 10.1111/j.14431661.2011.01232.x

14 Zhao X, Zhan Q, Xiang L, Wang Y, Wang X, Li A and Liu S: Clinicopathological characteristics of laterally spreading colorectal tumor. PLoS One 21: e94552, 2014. PMID: 24751926. DOI: 10.1371/journal.pone.0094552

15 Tang XW, Ren YT, Zhou JQ, Wei ZJ, Huang SL, Gao QP, Zhang XF, Yang JF, Gong W and Jiang B: Endoscopic submucosal dissection for laterally spreading tumors in the rectum $\geq 40 \mathrm{~mm}$. Tech Coloproctol 20: 437-443, 2016. PMID: 28348490. DOI: 10.3748/wjg.v23.i10.1843

16 Sato T, Konishi F, Togashi K, Ozawa A and Kanazawa K: Prospective observation of small "flat" tumors in the colon through colonoscopy. Dis Colon Rectum 42: 1457-1463,1999. PMID: 10566534. DOI: 10.1007/bf02235047

17 Rubio CA: Corrupted colonic crypt fission in carcinogen-treated rats. PLoS One 12: e0172824, 2017. PMID: 28273142. DOI: 10.1371/journal.pone.0172824

18 Rubio CA and Schmidt PT: Are non-dysplastic corrupted colonic crypts the initial recordable histological event in the development of conventional adenomas? Anticancer Res 38: 5315-5320, 2018 PMID: 30194183. DOI: 10.21873/anticanres.12858

19 Rubio CA and Schmidt PT: Disparate cell proliferation and p53overexpression in colonic crypts with normal epithelial lining found below the neoplastic canopy of conventional adenomas. J Pathol Clin Res 5: 154-163, 2019. PMID: 30821124. DOI: $10.1002 / \mathrm{cjp} 2.128$

20 Rubio CA and Schmidt PT: Crypts with corrupted shapes in nonpolypoid adenomas. Anticancer Res 39: 833-838, 2019. PMID: 30711964. DOI: 10.21873/anticanres.13182

21 Rubio CA, Rodensjö M, Duvander A, Mathies M, Garberg L and Shetye J: p53 up-regulation during colorectal carcinogenesis. Anticancer Res 34: 6973-6979, 2014. PMID: 25503123.

22 Baker AM, Cereser B, Melton S, Fletcher AG, Rodriguez-Justo M, Tadrous PJ, Humphries A, Elia G, McDonald SAC, Wright NA, Simons BD, Jansen M and Graham TA: Quantification of crypt and stem cell evolution in the normal and neoplastic human colon. Cell Rep 8: 940-947, 2014. PMID: 31116993. DOI: $10.1016 /$ j.celrep.2019.05.035

23 Rubio CA: Putative stem cells in mucosas of the esophagogastrointestinal tract. In: Stem cell, regenerative medicine and cancer. Singh SR (ed.). Nova Science Publishers Inc., New York, Chapter 10; pp. 279-308, 2010.

24 Boman BM and Fields JZ: An APC: WNT counter-current-like mechanism regulates cell division along the human colonic crypt axis: a mechanism that explains how APC mutations induce proliferative abnormalities that drive colon cancer development. Front Oncol 3: 244-254, 2013. PMID: 24224156. DOI: 10.3389/ fonc.2013.00244

25 Testa U, Pelosi E and Castelli G: Colorectal cancer: genetic abnormalities, tumor progression, tumor heterogeneity, clonal evolution and tumor-initiating cells. Med Sci (Basel) 6: 13-18, 2018. PMID: 29652830. DOI: 10.3390/medsci6020031

26 Levine DS and Haggitt RC: Normal histology of the colon. Am J Surg Pathol 13: 966-984, 1989. PMID: 2679155.

27 Rubio CA: The histologic structure of the large bowel mucosa and the evolution of the three pathways of colonic carcinogenesis in humans and in experimental animals. In: Recent Studies on Digestive System Anatomy, e-book 3: 112, 2018. http://openaccessebooks.com/digestive-systemanatomy.html

28 Dahl J and Greenson JK: Colon. In: Histology for Pathologists. Mills SE (eds.). Lippincott Williams \& Wilkins. Third Edition, Philadelphia, PA, USA Chapter 25, pp. 629-630, 2007.

29 Voorham QJ, Janssen J, Tijssen M, Snellenberg S, Mongera S, van Grieken NC, Grabsch H, Kliment M, Rembacken BJ, Mulder CJ, van Engeland M, Meijer GA, Steenbergen RD and Carvalho B: Promoter methylation of Wnt-antagonists in polypoid and nonpolypoid colorectal adenomas. BMC Cancer 13: 603-620, 2013. PMID: 24350795. DOI: 10.1186/1471-240713-603

30 Voorham QJ, Rondagh EJ, Knol DL, van Engeland M, Carvalho B, Meijer GA and Sanduleanu S: Tracking the molecular features of nonpolypoid colorectal neoplasms: a systematic review and meta-analysis. Am J Gastroenterol 108: 1042-1056, 2013. PMID: 23649184. DOI: 10.1038/ajg.2013.126

31 Takahashi T, Nosho K, Yamamoto H, Mikami M, Taniguchi H, Miyamoto N, Adachi Y, Itoh F, Imai K and Shinomura Y: Flattype colorectal advanced adenomas (laterally spreading tumors) have different genetic and epigenetic alterations from protrudedtype advanced adenomas. Mod Pathol 20: 139-147, 2007. PMID: 17143260. DOI: $10.1038 /$ modpathol 3800722

32 Jagan IC, Deevi RK, Fatehullah A, Topley R, Eves J, Stevenson $M$, Loughrey $M$, Arthur $\mathrm{K}$ and Campbell FC: PTEN phosphatase-independent maintenance of glandular morphology in a predictive colorectal cancer model system Neoplasia 15: 1218-1230, 2013. PMID: 24348097. DOI: 10.1593/neo.121516

33 Georgescu MM, Cote G, Agarwal NK and White CL 3rd: NHERF1/EBP50 controls morphogenesis of 3D colonic glands by stabilizing PTEN and ezrin-radixin-moesin proteins at the apical membrane. Neoplasia 16: 365-374, 2014. PMID: 24862762. DOI:10.1016/j.neo.2014.04.004

34 Goodlad RA, Lee CY and Wright NA: Cell proliferation in the small intestine and colon of intravenously fed rats: effects of urogastrone-epidermal growth factor. Cell Prolif 25: 393-404, 1992. PMID: 1391227. DOI: 10.1111/j.1365-2184.1992. tb01449.x 
35 Kudo S, Rubio CA, Teixeira CR, Kashida H and Kogure E: Pit pattern in colorectal neoplasia: endoscopic magnifying view. Endoscopy 33: 367-373, 2001. PMID: 11315901. DOI: 10.1055/ s-2004-826104

36 Rubio CA and Slezak P. The unique pathology of nonpolypoid colorectal neoplasia in IBD. Gastrointest Endosc Clin N Am 24: 455-468, 2014. PMID: 24975536. DOI: 10.1016/j.giec. 2014.03.009

37 Lambert R, Kudo SE, Vieth M, Allen JI, Fujii H, Fujii T, Kashida H, Matsuda T, Mori M, Saito H, Shimoda T, Tanaka S, Watanabe H, Sung JJ, Feld AD, Inadomi JM, O'Brien MJ, Lieberman DA,
Ransohoff DF, Soetikno RM, Zauber A, Teixeira CR, Rey JF, Jaramillo E, Rubio CA, Van Gossum A, Jung M, Jass JR and Triadafilopoulos G: Pragmatic classification of superficial neoplastic colorectal lesions. Gastrointest Endosc 70: 1182-1199, 2009. PMID: 19879563. DOI: 10.1016/j.gie.2009.09.015

Received August 5, 2019 Revised August 10, 2019 Accepted August 14, 2019 